\title{
The Effect of Produce Purchasing Behavior on Adult Obesity and Body Weight: Evidence from Household- Level Scanner Data
}

\author{
Richard Volpe, Xiaowei Cai, Christiane Schroeter, and \\ Lisa Mancino
}

\begin{abstract}
We use household scanner data, paired with rich demographics and merged with self-reported measures of obesity and body mass index (BMI), to investigate the potential effects of fruit and vegetable purchasing behavior on adult obesity and body weight. We find that increasing household fruit and vegetable expenditure shares by one percentage point decreases the multiyear incidence of adult obesity by approximately 9 percent and average adult BMI by 1.4 percent, controlling for a host of potential confounding factors and measures of lifestyle choices. The results are robust to specification choice, although estimated impacts differ by gender. Our findings help quantify the potential impacts of government efforts aimed at increasing fruit and vegetable intake.
\end{abstract}

Key words: overweight, diet quality, body weight, obesity, BMI, household scanner data JEL Classifications: R22, I12, Q13

Richard Volpe, Xiaowei Cai, and Christiane Schroeter, Agribusiness Department, California Polytechnic State University, San Luis Obispo, California. Lisa Mancino, Research Economist, Food Economics Division, USDA Economic Research Service. Correspondence: Richard Volpe, Agribusiness Department, California Polytechnic State University, San Luis Obispo, California. Email: rvolpe@calpoly.edu

The authors are grateful to Tim Park, Abigail Okrent, and Annemarie Kuhns, for helpful comments on earlier versions of the manuscript. The authors also received valuable feedback from attendees at the Agricultural and Applied Economics Association and Western Agricultural Economics Association annual meetings. Finally, the authors are indebted to the editor and to two anonymous referees who provided numerous invaluable suggestions to improve our work. Disclaimer: Any opinions, findings, recommendations, or conclusions are those of the authors and do not necessarily reflect the views of the Economic Research Service, U.S. Department of Agriculture. The analysis, findings, and conclusions expressed in this study also should not be attributed to either Nielsen or Information Resources, Inc. (IRI). This research was conducted in collaboration with USDA under a Third Party Agreement with IRI. Funding information: This research has been supported by California State University Agricultural Research Initiative Campus Competitive Grant, San Luis Obispo, and the intramural research program of the US Department of Agriculture, Economic Research Service. The findings and conclusions were not formally disseminated by the US Department of Agriculture and should not be construed to represent any agency determination or policy. The analysis, findings, and conclusions expressed in this study also should not be attributed to either Nielsen or Information Resources, Inc. (IRI). This research was conducted in collaboration with USDA under a Third Party Agreement with IRI.

Agricultural and Resource Economics Review 48/2 (August 2019) 253-273

(C) The Author(s) 2019. This is an Open Access article, distributed under the terms of the Creative

Commons Attribution licence (http://creativecommons.org/licenses/by/4.0/), which permits unrestricted re-use, distribution, and reproduction in any medium, provided the original work is 
Research across several disciplines has established that food choices and dietary habits of most U.S. Americans are out of sync with recommendations. According to the National Health and Nutritional Examination Survey (NHANES), the consumption of fruits and vegetables, lean meats, seafood, and whole grains is too low, while the intake of refined grains, added sugars, and saturated fats is too high (USDA 2015). These insights are also readily available from the United States Department of Agriculture's (USDA) longrunning Healthy Eating Index (HEI), which assesses the dietary quality based on a representative sample of the U.S. population. The Center for Nutrition Policy and Promotion (CNPP) of the USDA used the HEI-2010 to compare U.S. diet quality between 2001 and 2002 and 2007 and 2008 and determined that average HEI scores increased slightly from 51.9 to 53.5 (CNPP 2013). In both time periods, average HEI scores reflected considerable room for improvement.

Coinciding with poor average U.S. dietary quality, the incidence of overweight and obesity has been on the rise. Over one-third of U.S. adults, or 76 million Americans, were obese as of 2012 (Ogden et al. 2015). The total medical care costs related to obesity were estimated at approximately $\$ 147$ billion as of 2008 (Finkelstein et al. 2009). There is little question that more work is needed to understand the causes and consequences of obesity as well as the means by which policy and industry might influence the problem.

Our study examines linkages between fruit and vegetable spending patterns, an important component of a healthy diet, and body weight or obesity. An extensive scientific literature (see Van Duyn and Pivonka 2000) has demonstrated the health-protective benefits of fruit and vegetable consumption. In addition, the 2010 Dietary Guidelines for Americans (DGA) strongly emphasizes increased fruit and vegetable consumption for all Americans (CNPP 2010). We focus specifically on the purchase patterns for fruits and vegetables among U.S. households, and use expenditure shares for these foods as our key measurement of interest to tie our findings to policy recommendations.

Using a large dataset on U.S. household grocery purchases, demographic information and self-reported health outcomes, we test for relationships between the grocery expenditure share on fruits and vegetables and obesity as well as the average body mass index (BMI) among adults. Previous studies have examined the impacts of dietary quality or even fruit and vegetable consumption specifically on health outcomes such as body weight (Chen et al. 2016; Kaiser et al. 2014). Our study breaks new ground and contributes to the literature in two important ways.

First, we use a large household-level dataset that allows us to assess severa; lifestyle choices related to health and weight, such as attitude toward physical exercise (Sarma et al. 2014). To establish the relationship between fruit and vegetable purchases and health outcomes, we link the 2008-2012 Information Resources Incorporated (IRI) household data on food purchases with the 2010-2012 IRI MedProfiler data. The MedProfiler data consists of 
self-reported health outcomes for all household members. Fruit and vegetable expenditures are readily observable using point-of-sale scanner data, and they provide a longitudinal aspect to our analysis that is rarely available in studies of this nature, many of which have relied on dietary recall data. The breadth and granularity of household- and individual-level controls in our data also lends support to our identification strategy.

Second, we aim to contribute to ongoing policy discussions about low fruit and vegetable consumption among Americans. The federal government has established several policy initiatives aimed at promoting a higher intake level of fruits and vegetables. These include the DGA, the Let's Move! Campaign, MyPlate, 5-A-Day and its successor, Fruits \& Veggies-More Matters. Hence, there is an evident market for information about recommended fruit and vegetable consumption habits and the associated linkages to health outcomes. In our analysis, we quantify our results by showing the impact of a 1 percentage point increase in fruit and vegetable purchases on the likelihood of obesity (or on BMI). By quantifying the associations between fruit and vegetable purchasing decisions and health outcomes that bear significant medical and social costs, our findings may inform the extent to which the government invests in educational efforts or policy tools intended to increase fruit and vegetable purchases in the United States.

Using a sample of over 18,000 households, we seek to quantify the association between fruit and vegetable expenditures and weight-related health outcomes by gender, by controlling for lifestyle choices, age, income, race, marital status, education, and geographic region to illustrate the relative importance of fruits and vegetables among food categories. In our sample, the same households appear in both the IRI household data and the MedProfiler data. In addition, only those households who participate in the panel consistently over time are used in our fixed effects estimation, resulting in approximately 18,000 households each year between 2010 and 2012. Our findings indicate that increased fruit and vegetable expenditures, as a share of the household food-at-home budget, are associated with a significantly reduced obesity rate as well as BMI. The estimated relationships are generally consistent to specification choice. However, potentially important differences in our key associations emerge when comparing results across gender.

\section{Background}

Diet, body weight, and health outcomes are intimately linked. According to the Centers for Disease Control and Prevention (CDC), obesity is associated with a large number of ailments and health risks, including type 2 diabetes, high blood pressure, high cholesterol, cardiovascular diseases, and morbidity (Avenell et al. 2004; Ahima and Lazar 2013). For the prevention and treatment of obesity, the CDC recommend eating a healthy diet and limiting caloric intake. Accordingly, researchers have applied numerous methods to investigating and quantifying 
the relationships between food intake and obesity. Examples of impactful metaanalyses on these topics include the impact of dietary sugars on body weight (Te Morenga et al. 2013), the health impacts of soft drink consumption (Vartanian et al. 2007), and understanding the impacts of low-carbohydrate diets (Nordmann et al. 2006).

Our interest in the determinants of obesity and body weight also stems from the incidence of related health care costs. In addition to the aforementioned health care costs directly associated with obesity and overweight, several related ailments among U.S. adults are responsible for substantial health care costs. Approximately 29 million U.S. adults have diabetes, which led to an estimated \$176 billion in direct medical costs in 2012 (CDC 2014). The CDC estimates that one in three U.S. adults has high blood pressure, and one in three U.S. adults has high cholesterol, where these cases are defined by exceeding the respective established medical thresholds for concern. High cholesterol and high blood pressure are associated with several heart ailments that are estimated to be over $\$ 300$ billion in health care costs (CDC 2011).

Economists have been interested in these issues for decades. Many studies have applied economic modeling to questions surrounding food choices and health. A handful of studies (Howard et al. 2006; Powell 2009; Oyebode et al. 2014) have even sought to identify empirically linkages between dietary quality, food choices, and health outcomes in panel settings. Estimated effects in this respect have typically been small but significant. For example, using data very similar to ours, Chen et al. (2016) find that a one-unit increase in overall dietary quality is associated with a 7 percent lower likelihood of obesity. Our key finding with respect to obesity is similar in magnitude.

We discuss the studies and findings that have been most influential to the present research, as they have informed the controls we have used in our econometric modeling. Morgan (1986) and Wilde et al. (1999) identified a significant income effect, with higher-income people generally consuming healthier diets. Income has been shown to be an important determinant of food expenditures, by broad category, as well (Okrent and MacEwan 2014). Adelaja et al. (1997) identified important differences across races, e.g., that most minorities groups consume less calcium than whites. Gao et al. (2013) is among the more recent studies to demonstrate the positive impact of education level on food choices. Blaylock et al. (1999) and Mancino and Newman (2007) studied how time constraints influence food preparation and food choices, finding that working longer hours is associated with less food preparation at home.

In studies of both health outcomes, food choices, and diet quality, gender has emerged as a significant consideration. Among U.S. adults, obesity rates as well as changes in those rates over time differ for men and women (Wang and Beydoun 2007; Flegal et al. 2012, 2016). Moreover, there may be gender differences in the relationship between dietary quality and health outcomes such as obesity (Mozaffarian et al. 2011). Dietary quality may differ significantly by gender, with research showing that women have overall healthier diets than men (Wang et al. 2014). Finally, households with a single 
female head are considerably more likely to be food insecure or to lack access to the foods necessary to meet the DGA, compared with households with male heads or married household heads (Coleman-Jensen et al. 2014). We, therefore, conduct a detailed analysis by gender.

From a nutritional perspective, fruits and vegetables are the foundation of a healthy diet. Van Duyn and Pivonka (2000) conducted a comprehensive review for the epidemiological profession, by providing an overview of the scientific literature on the health effects of fruits and vegetables. They concluded that the scientific evidence supports the contention that fruits and vegetables have vast and varied protective effects for many major organs and against a range of diseases and ailments. These include obesity and overweight, as well as diabetes, cancer, and hypertension. Mandal and Powell (2014) noted that fruits and vegetables are key "low-energy dense" foods that are negatively and importantly associated with obesity rates among children. Capacci and Mazzocchi (2011) showed that the 5-a-day program increased fruit and vegetable consumption in the United Kingdom by 0.3 portions.

But U.S. fruit and vegetable consumption lags behind other developed nations and is widely out of sync with dietary recommendations. For example, Canadians consume more than twice the per-capita quantities of bananas, apples, and oranges than Americans (Richards and Patterson 2005). Kimmons et al. (2009) used the 2003-2004 NHANES and determined that fewer than one in 10 Americans met their caloric recommendations for fruit and vegetable intake. Similar findings on fruit and vegetable consumption have also been found when looking at specific demographic subgroups, such as college students (Huang et al. 2003), children (Krebs-Smith et al. 1996), low-income households (Cassady et al. 2007), and pregnant women (Bodnar and Siega-Riz 2002).

From a policy perspective, fruit and vegetable intake has been the focus of several studies on food access and food security. These works reflect efforts to inform policy makers regarding actual fruit and vegetable purchases. Rose and Richards (2004) and Bustillos et al. (2008) used survey data to show that low-income households are more likely to have lower dietary quality and a higher average incidence of adverse health outcomes, relative to higherincome households. A separate line of research, which does not measure or account for dietary quality, has investigated the role of food assistance programs, particularly the Supplemental Nutrition Assistance Program (SNAP), on fruit and vegetable expenditures. Dong and Lin (2009) as well as Leung et al. (2012) have found a small impact of SNAP participation in this regard. Leibtag and Kumcu (2011) demonstrated that regional food price differences may affect the purchasing power of SNAP for fruits and vegetables.

\section{Data and Statistics}

Our study departs from much of the existing research on food choices and diet quality, in that we use household-level scanner data. Most previous work has 
relied upon dietary recall data, such as the NHANES data. As we discuss the properties of our data, we take care to describe the advantages and disadvantages of our approach, relative to the use of dietary recall data.

We use the 2008-2012 IRI Household Panel Data (henceforth called the "Panel"). The Panel is based on a sample of over 100,000 households nationwide. Household Panel members could either be volunteers or recruited by IRI. Participating households use hand-held scanners to scan the dates of their product purchases, universal product code, purchase volume, and total expenditures. ${ }^{1}$ As a result, our data includes information about the comprehensive grocery purchases for these households, including the location of grocery purchases and the prices paid.

Household purchases set the data frequency in the raw Panel data. Households participating in the Panel may make hundreds of shopping trips per year, and we aggregate to the annual level for all variables. We have several years of data for many thousands of households. This is in contrast to dietary recall data, which typically consists of 2 days' worth of dietary intake. The purchase data are accompanied by household-level demographics, which allow us to control for a wide range of important variables, including income, race and ethnicity, age, education, gender, marital status, and geographic location. The Panel does not include information about food preparation or actual consumption, or foods purchased and consumed outside of the home such as at restaurants or other institutions. We assume that at-home purchases are a close proxy for at-home consumption.

We measure fruit and vegetable consumption by means of expenditure shares, as reflected by grocery purchases. Our key variable of interest, FruitVegShare, includes fresh, frozen, and canned fruits and vegetables, as defined within the IRI data dictionary. We argue that increases in the expenditure share attributed to fruits and vegetables indicate unambiguous increases in dietary quality. By using shares, we preclude the possibility that households increase their fruit and vegetable expenditures in lockstep with other foods that are less aligned with the DGA. That is, we are not simply capturing changes in aggregate household food spending. USDA has devised food spending guidelines for shoppers on any budget, to meet the DGA (Carlson et al. 2007). Preliminary statistics indicated that average household in the Panel far exceeds recommendations for refined grains, red meat, sugars and sweets and falls far short of recommendations for whole grains, lean protein sources, and all fruit and vegetable categories. ${ }^{2}$ Therefore, as

\footnotetext{
1 Random weight purchases, such as the fresh loose-weight fruit and vegetable products were discontinued in 2006. Participants in the Panel, since that time, are asked to record their total expenditures for fruits and vegetables per shopping trip. We, therefore, do not have granular data on the specific fruits and vegetables being purchased or the quantities involved, which is another reason we rely on using expenditure shares to conduct our analysis.

2 These calculations are available from the authors upon request.
} 
expenditure shares increase for fruits and vegetables, households are unlikely to be substituting spending in other, relatively healthful categories, but rather, are substituting away from categories with less healthful foods. ${ }^{3}$

To assess health outcomes, we merge the Panel with the 2010-2012 IRI MedProfiler data. The MedProfiler data consists of a subset of the Panel, approximately 40,000 households, who also respond to a detailed annual survey regarding health and well-being. We focus our analysis only on those households participating in both datasets, and, therefore, providing purchase records and demographics matched with self-reported health outcomes. Respondents indicate on a five-point scale the extent to which they suffer from obesity. The possible responses include: suffer but do not treat, suffer and treat with over-the-counter medication, suffer and treat with prescription medication, suffer and treat with both over-the-counter and prescription medication, and do not suffer. Restricting our attention to adults, ${ }^{4}$ we calculate the binary Obesity, which serves as one of our key variables of interest, as being equal to one for households in which any adults report suffering from obesity. ${ }^{5}$

Researchers have long recognized the biases associated with self-reported health data. Rowland (1990) found that survey respondents were prone to underreport their weight, and that this bias increased among overweight people. It is, therefore, worth comparing the MedProfiler statistics to findings from NHANES. Among the MedProfiler sample, we find that the share of adults reporting obesity is approximately 13 percent. However, the average adult BMI for the sample was 28.8, with values ranging from 18.9 to 46.8, and a standard deviation of 7.5. Flegal et al. (2012) used 2009-2010 NHANES data and found that 35 percent of adults were obese, and the

\footnotetext{
3 As a robustness check on our results, we also estimated all of our regressions using a measure of overall dietary quality, calculated by household and year. In this effort, we follow Volpe and Okrent (2012) in calculating the USDAScore, a unitless measure of dietary quality, with higher numbers reflecting stronger adherence to the DGA. The correlation between fruit and vegetable expenditure shares and USDAScore is rather weak $(0.29,0.28$, and 0.34 for 2010,2011 , and 2012, respectively). None of our estimated associations of interest change importantly with USDAScore included. Given that USDAScore is calculated using fruit and vegetable expenditure shares, we recognize that including USDAScore complicates the interpretation of our key coefficients of interest and we have elected only to report estimation results that exclude USDAScore. Results including USDAScore are available upon request. Readers interested in the complete details behind the approach may refer to Volpe and Okrent (2012). For additional studies that have used this measure, see Volpe et al. (2013), Chen et al. (2016), and Volpe et al. (2018).

4 Health outcome data for children in the MedProfiler dataset are very thin. As we discuss below, the IRI Panel skews older than the general population, meaning that relatively few households report having children under the age of 18. Of those households, health outcomes are not reported for children.

5 Eight percent of all households in our dataset include a mix of adults who are obese and not obese. Our decision to treat the Obesity variable as a binary was made largely to facilitate the use of limited dependent variable regression techniques.
} 
average adult BMI was 28.7, as calculated based on reported height and weight. Therefore, MedProfiler respondents are accurately reporting their height and weight, but are underreporting or misunderstanding the extent to which they are obese.

Owing to this potential issue with the self-reported incidence of obesity, we also calculate and analyze adult BMI in our MedProfiler dataset (AdultBMI). Therefore, we are able to determine the impact of fruit and vegetable purchase behavior on the discrete obesity classification as well as on incremental changes in adult BMI. This widens the implications of our potential findings, given that fruit and vegetable purchase and consumption may affect the body weight of individuals who are not obese. Additionally, we recognize that survey respondents have the potential to underreport their status as obese or to misreport their weight. We are able to investigate the robustness of our findings by measuring weight outcomes in two ways. In our dataset, across all years, the correlation between average adult BMI and fruit and vegetable expenditure share is -0.021 . The average fruit and vegetable expenditure share for households with Obesity equal to 1 is 13.31 percent and for households with Obesity equal to 0 is 13.9 percent .

The MedProfiler data also includes several survey questions that we use to measure lifestyle choices, which are important as controls. We calculate household scores for exercise activity, vitamin intake, and omega-3 supplement usage. The possible responses for these questions are $1=$ Never, $2=$ Sometimes, and $3=$ Frequently. We average these responses across all adults within households to calculate these lifestyle scores. Table 1 provides summary statistics and definitions for the variables used in our analysis.

\section{Methodology and Results}

Our empirical strategy for identifying a relationship between fruit and vegetable purchases and health outcomes is two-pronged. Our empirical models for the binomial logistic estimation and ordinary least squares (OLS) estimation are as follows:

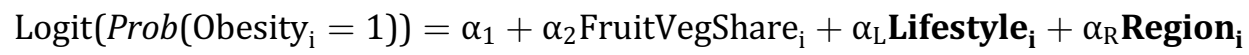

$+\alpha_{\mathrm{E}}$ Education $_{\mathbf{i}}+\alpha_{\mathrm{R}}$ Race $_{\mathbf{i}}+\alpha_{\mathrm{D}}$ Demographics $_{\mathbf{i}}+\theta_{\mathrm{i}}$

$$
\begin{aligned}
& \text { AdultBMI }_{\mathrm{i}}=\beta_{1}+\beta_{2} \text { FruitVegShare }_{\mathrm{i}}+\beta_{\mathrm{L}} \text { Lifestyle }_{\mathbf{i}}+\beta_{\mathrm{R}} \text { Region }_{\mathbf{i}} \\
& +\beta_{\mathrm{E}} \text { Education }_{\mathbf{i}}+\beta_{\mathrm{R}} \text { Race }_{\mathbf{i}}+\beta_{\mathrm{D}} \text { Demographics }_{\mathbf{i}}+\mu_{\mathrm{i}}
\end{aligned}
$$

where the odds ratio of household-level incidence of obesity in equation (1) or average AdultBMI in equation (2) for household $i$ is a function of fruit and vegetable expenditure shares (FruitVegShare), a vector of variables measuring lifestyle choices (Lifestyle), a vector of geographic effects (Region), 
Table 1. Summary Statistics for the Variables Used

\begin{tabular}{|c|c|c|c|c|}
\hline Variable & Description & $\mathbf{N}$ & Mean & St. Dev. \\
\hline Obesity & $\begin{array}{l}\text { Dummy }=1 \text { if at least one household } \\
\text { head suffers from obesity }\end{array}$ & 18,562 & 0.13 & \\
\hline MheadObesity & $\begin{array}{l}\text { Dummy }=1 \text { if the male head within } \\
\text { households suffering from obesity }\end{array}$ & 13,809 & 0.07 & \\
\hline FheadObesity & $\begin{array}{l}\text { Dummy }=1 \text { if the female head within } \\
\text { households suffering from obesity }\end{array}$ & 15,824 & 0.09 & \\
\hline AdultBMI & $\begin{array}{l}\text { The average BMI among adults in the } \\
\text { household }\end{array}$ & 18,355 & 28.85 & 7.56 \\
\hline MheadBMI & $\begin{array}{l}\text { The average BMI among male heads in } \\
\text { the household }\end{array}$ & 13,647 & 28.97 & 6.18 \\
\hline FheadBMI & $\begin{array}{l}\text { The average BMI among female heads } \\
\text { in the household }\end{array}$ & 15,578 & 28.85 & 12.32 \\
\hline $\begin{array}{l}\text { FruitVegShare } \\
\text { (percent) }\end{array}$ & $\begin{array}{l}\text { The share of food-at-home purchases } \\
\text { attributed to fruits and vegetables }\end{array}$ & 18,562 & 13.82 & 6.16 \\
\hline ExerciseScore & $\begin{array}{l}\text { The average exercise score among } \\
\text { adults in the household }\end{array}$ & 18,562 & 1.90 & 0.69 \\
\hline VitaminScore & $\begin{array}{l}\text { The average vitamin score among } \\
\text { adults in the household }\end{array}$ & 18,562 & 1.75 & 0.78 \\
\hline Omega3Score & $\begin{array}{l}\text { The average omega } 3 \text { score among } \\
\text { adults in the household }\end{array}$ & 18,562 & 2.09 & 0.69 \\
\hline Midwest & $\begin{array}{l}\text { Dummy }=1 \text { if household is in the } \\
\text { Midwest }\end{array}$ & 18,562 & 0.18 & \\
\hline South & $\begin{array}{l}\text { Dummy }=1 \text { if household is in the } \\
\text { South }\end{array}$ & 18,562 & 0.36 & \\
\hline Northeast & $\begin{array}{l}\text { Dummy }=1 \text { if household is in the } \\
\text { Northeast }\end{array}$ & 18,562 & 0.27 & \\
\hline HHIncome & $\begin{array}{l}\text { Household annual income, in ten } \\
\text { thousand U.S. dollars }\end{array}$ & 18,562 & 5.99 & 3.58 \\
\hline Fulltime_F & $\begin{array}{l}\text { Dummy }=1 \text { if female head of } \\
\text { household works } 35 \text { hours or more } \\
\text { per week }\end{array}$ & 18,562 & 0.41 & \\
\hline Fulltime_M & $\begin{array}{c}\text { Dummy = } 1 \text { if male head of household } \\
\text { works } 35 \text { hours or more per week }\end{array}$ & 18,562 & 0.27 & \\
\hline College_F & $\begin{array}{l}\text { Dummy }=1 \text { if female head of } \\
\text { household graduated college }\end{array}$ & 18,562 & 0.28 & \\
\hline College_M & $\begin{array}{l}\text { Dummy }=1 \text { if male head of household } \\
\text { graduated college }\end{array}$ & 18,562 & 0.22 & \\
\hline GradSchool_F & $\begin{array}{l}\text { Dummy }=1 \text { if female head of } \\
\text { household attended graduate } \\
\text { school }\end{array}$ & 18,562 & 0.11 & \\
\hline
\end{tabular}


Table 1. Continued

\begin{tabular}{llccc}
\hline Variable & \multicolumn{1}{c}{ Description } & N & Mean & St. Dev. \\
\hline GradSchool_M & $\begin{array}{l}\text { Dummy }=1 \text { if male head of household } \\
\text { attended graduate school } \\
\text { White }\end{array}$ & 18,562 & 0.10 & \\
Asian & $\begin{array}{l}\text { Dummy }=1 \text { if household reports } \\
\text { white as race } \\
\text { Dummy }=1 \text { if household reports } \\
\text { Married }\end{array}$ & 18,562 & 0.85 & 18,562 \\
Asian as race & $\begin{array}{l}\text { Dummy }=1 \text { if household heads are } \\
\text { married }\end{array}$ & 18,562 & 0.64 & \\
HHAge & Average age of household adults & 18,562 & 55.39 & 13.01 \\
\hline
\end{tabular}

${ }^{a}$ A very small percentage of households in the IRI Panel report having multiple household heads of the same gender. In these cases, the gender-specific obesity dummy is calculated as 1 if any of the household heads for the relevant gender report being obese.

Source: Authors' calculations using IRI Household Panel and IRI MedProfiler Data.

a vector of educational attainment variables (Education), a vector of race and ethnicity dummy variables (Race), and a vector of additional household demographic controls (Demographics). In terms of dietary choices, FruitVegShare is calculated as the share of total annual grocery expenditures attributed to fruits and vegetables.

Our key explanatory variable of interest is FruitVegShare, and we expect to estimate negative coefficients for this variable, owing to the body of evidence supporting the health protectiveness of these foods. Our identification strategy hinges on the notion that body weight and overweight/obesity status can change in a matter of years. Given that the average age in the MedProfiler sample is 55, our data is skewed toward an age above the general U.S. population. Wang et al. (2016) tracked the body weight status of over 3,000 adults aged between 40 and 55 years at the start of the study. The authors identified four distinct body-weight trajectories within the sample, indicating that body weight and obesity status can change, even among middle-aged adults. We control for age, although due to the nature of our sample, our expectations for this variable are ambiguous.

Given that we lack access to a comprehensive or consistent measure of nutritional content or serving size across products, we are not able to measure fruit and vegetable consumption as a share of calories in our analysis. Therefore, it is possible that changes in fruit and vegetable expenditure shares could be due to changes in relative prices. However, we argue that measurement error due to relative food prices is only an issue if households systematically purchase fruits and vegetables at stores different from those at which they buy other groceries. Statistics from our dataset suggest that this is not the case. For example, we compared fruit and vegetable purchases of households that primarily shop at supermarkets with 
those of households that shop predominantly elsewhere. Households in the highest quartile of supermarket shoppers have an average FruitVegShare of 14.05 percent. For households in the bottom quartile, this value is 12.55 percent. ${ }^{6}$ This indicates a modest difference between these two groups of shoppers.

The vectors of controls include variables calculated using the Panel and the MedProfiler datasets. The Lifestyle vector includes household scores based on the responses to questions on exercise activity, vitamin intake, and omega3 supplementation. We model these as measures of lifestyle choices or the unobservable demand for health, and thus we expect each of these factors to be negatively associated with measures of body weight.

The Region vector indicates if households are located in the Northeast, Midwest, South, or West. Through this vector we aim to capture geographic differences in obesity rates, attitudes toward health, average dietary quality, and food prices. As an example, the CDC calculates and reports obesity rates by state each year. It is readily apparent as of 2016 that obesity rates are the highest on average in the southern and Midwestern states and the lowest on average in the western and northeastern states (CDC 2017).

The remaining controls consist of demographic variables. The Education vector indicates, by gender of the household heads, the highest level of education attained. Owing to the literature cited in support of this control, we expect that education will be negatively associated with obesity and BMI. The Race vector indicates if households categorize themselves as White, Black, Asian, or other. ${ }^{7}$ We have no clear expectations for these variables, particularly given that the Panel is predominantly white. And, finally, the Demographics vector includes measures of household income and the aforementioned average age of adults. We expect income to be negatively associated with obesity and BMI.

Our logistic and OLS approaches seek to identify the impacts of purchasing behavior by means of cross-sectional variation across households. Therefore, we model the 2012 Obesity and AdultBMI values as functions of the average values for FruitVegShare for all available years (maximum of 6) of data for the respective households. We do not assume that 1 year of observed purchase behavior is likely to have a meaningful impact on body weight or health outcomes generally. We also follow this approach to address concerns regarding dual-causality, as health outcomes are a plausible function of earlier behavior but the reverse cannot be true. Nevertheless, we recognize that unobservable household characteristics, e.g., the demand for health and longevity, may be correlated with both the error term and fruit and vegetable

\footnotetext{
6 Additional statistics regarding store switching and fruit and vegetable expenditures are available from the authors upon request.

7 The IRI data also include a dummy for households identifying as Hispanic, which is distinct from the categorical race variable. Therefore, for example, a household may identify as both white and Hispanic.
} 
purchases. Using the average values for FruitVegShare, we are able to capture the multiyear effect of households' past fruit and vegetable purchases, measured as measures of past behavior. Similarly, we believe that the lifestyle variables tend to have the same type of long-term impact on health as the food purchase behavior; therefore, we use the average values for these variables as well in equations (1) and (2).

Furthermore, we revise equations (1) and (2) by including both the cross sectional and longitudinal effects. Our dependent variable is again adult Obesity or AdultBMI at time $t$. This way, we are able to estimate our regression in a panel setting, using household fixed effects. In equations (3) and (4) below, we use Obesity and AdultBMI for all available years, 20102012, and model these as functions of FruitVegShare using the most recent 3 years of data. For example, 2012 health outcomes are modeled as a function of average fruit and vegetable expenditures for 2010-2012.

$\operatorname{Logit}\left(\operatorname{Prob}\left(\right.\right.$ Obesity $\left.\left._{i t}=1\right)\right)=\rho_{1}$ FruitVegShare $_{i t}+\rho_{\mathrm{L}}$ Lifestyle $_{\text {it }}+\rho_{\mathrm{R}}$ Region $_{\mathbf{i}}$

$$
+\rho_{\mathrm{E}} \text { Education }_{\mathbf{i}}+\rho_{\mathrm{R}} \text { Race }_{\mathbf{i}}+\rho_{\mathrm{D}} \text { Demographics }_{\mathbf{i t}}+\mu_{\mathrm{it}}
$$

$$
\begin{aligned}
& \text { AdultBMI }_{i t}=\gamma_{1}+\gamma_{2} \text { FruitVegShare }_{i t}+\gamma_{\mathrm{L}} \text { Lifestyle }_{\mathbf{i t}}+\gamma_{\mathrm{R}} \text { Region }_{\mathbf{i}} \\
& +\gamma_{\mathrm{E}} \text { Education }_{\mathbf{i}}+\gamma_{\mathrm{R}} \text { Race }_{\mathbf{i}}+\gamma_{\mathrm{D}} \text { Demographics }_{\mathbf{i t}}+\varepsilon_{\mathrm{it}},
\end{aligned}
$$

Similar to the variables used in equations (1) and (2), the odds ratio of household-level incidence of obesity in equation (3) or average AdultBMI in equation (4) for household $i$ at time $t$ is a function of household fruit and vegetable expenditure shares at time $t$ (FruitVegShare), household lifestyle choices at time $t$ (Lifestyle), a vector of geographic effects (Region), a vector of educational attainment variables (Education), a vector of race and ethnicity dummy variables (Race), and a vector of additional household demographic controls (Demographics) such as age that vary with time.

Through this approach we increase our sample size substantially. In addition, the usage of household-level fixed effects controls for unobservable characteristics that might relate to household purchasing decisions and health outcomes, mitigating potential concerns regarding dual causality or endogeneity that cannot be addressed using a lag structure. In all of our models, we checked for multicollinearity using the variance inflation factor, and found no values above two. We also estimate using robust standard errors, to account for potential heteroscedasticity resulting from variation in total fruit and vegetable expenditures across households.

\section{Results and Discussion}

We begin by estimating equations (1) and (2) using logistic regression for the binary Obesity variable and OLS estimation for the continuous AdultBMI 
variable. ${ }^{8}$ Selected results are reported in Table 2, and the complete set of results are available from the authors upon request. Importantly, we find that increased fruit and vegetable expenditure shares are associated with significant decreases in the incidence of high obesity among adults. We also find a negative and significant relationship with AdultBMI.

The interpretation of the estimated coefficients on FruitVegShare vary between the logit and OLS estimations. To aid with interpretation, we calculate and report the estimated marginal effect for FruitVegShare with respect to Obesity and elasticities with respect to AdultBMI. We find that a one percentage point increase in FruitVegShare is associated with an approximately 9 percent decrease in the probability of being obese, within households. With respect to BMI, the estimated impact is a 1.4 percent decrease in average BMI among adults. These associations are both statistically and economically significant. Moreover, given the gap between the average American's consumption of fruit and vegetables and federal recommendations, they suggest that considerable reductions in the U.S. obesity rate can be achieved through dietary changes.

In most cases, the coefficient estimates for our controls have the expected signs. The lifestyle factors (exercise, vitamin intake, and omega-3 supplement intake), which are not intended to demonstrate causality, but rather to control for preferences toward health and well-being, are generally negative and significant. We corroborate the findings of previous studies (e.g., Schroeter et al. 2013), in that our lifestyle vector seems to serve as another marker for healthy eating.

Income is negatively associated with adult obesity and BMI, supporting the body of work on socioeconomic status and health outcomes (e.g., Stewart et al. 2003). We find evidence that average age is negatively associated with adult body weight. Recall that age in the Panel averages well above the general population and exhibits relatively little variation, and, therefore, estimation results regarding age ought to be interpreted with caution..$^{9}$ Given the age distribution of our data, our results indicate that as adults advance through middle age, they are more likely to lose than gain weight, all else equal.

Across gender, the results for equations (1) and (2) show some intriguing differences that may warrant further investigation. The estimated coefficient on Obesity is negative and not significant for male household head, but for female household head it is highly significant. The coefficient on BMI for male household head is negative and significant, indicating that a 1 percent

\footnotetext{
8 Following a reviewer's recommendation, we also experimented with treating obesity within households as a score ranging from 0 to 1 , based on the share of adults indicating that they suffer from obesity. In this setting, we estimated (1) using a Tobit approach, to address the large number of zeroes in the data. The results also corroborated our key findings of interest, and these results are available upon request.

9 We experimented with a quadratic treatment of age to capture a potential nonlinear effect, but the variation in age was too small for this to be meaningful.
} 
Table 2. Selected Results for Estimating Equations (1) and (2) Using Only 2012 Health Outcomes

\begin{tabular}{|c|c|c|c|c|c|c|}
\hline & \multicolumn{3}{|c|}{ Obesity } & \multicolumn{3}{|c|}{ AdultBMI } \\
\hline & \multicolumn{3}{|c|}{ Estimation Technique: Logit } & \multicolumn{3}{|c|}{ Estimation Technique: OLS } \\
\hline & Entire Sample & Men $^{c}$ & Women & Entire Sample & Men & Women \\
\hline FruitVegShare & $\begin{array}{l}-0.856^{* *} \\
(0.427)\end{array}$ & $\begin{array}{c}-0.463 \\
(0.633)\end{array}$ & $\begin{array}{l}-1.486^{* * *} \\
(0.542)\end{array}$ & $\begin{array}{l}-2.879^{* * *} \\
(1.090)\end{array}$ & $\begin{array}{l}-4.714^{* * *} \\
(0.957)\end{array}$ & $\begin{array}{l}2.519 \\
(2.149)\end{array}$ \\
\hline ExerciseScore & $\begin{array}{l}-0.481^{* * *} \\
(0.034)\end{array}$ & $\begin{array}{l}-0.571^{* * *} \\
(0.051)\end{array}$ & $\begin{array}{l}-0.399^{* * *} \\
(0.041)\end{array}$ & $\begin{array}{l}-2.089^{* * *} \\
(0.088)\end{array}$ & $\begin{array}{l}-1.739^{* * *} \\
(0.078)\end{array}$ & $\begin{array}{l}-2.298^{* * *} \\
(0.171)\end{array}$ \\
\hline VitaminScore & $\begin{array}{c}-0.029 \\
(0.031)\end{array}$ & $\begin{array}{c}-0.053 \\
(0.046)\end{array}$ & $\begin{array}{c}-0.023 \\
(0.038)\end{array}$ & $\begin{array}{l}-0.077 \\
(0.082)\end{array}$ & $\begin{array}{c}-0.053 \\
(0.072)\end{array}$ & $\begin{array}{c}-0.058 \\
(0.161)\end{array}$ \\
\hline Omega3Score & $\begin{array}{c}-0.067^{*} \\
(0.035)\end{array}$ & $\begin{array}{c}-0.022 \\
(0.052)\end{array}$ & $\begin{array}{c}-0.077^{*} \\
(0.043)\end{array}$ & $\begin{array}{c}-0.160^{*} \\
(0.093)\end{array}$ & $\begin{array}{c}-0.147^{*} \\
(0.080)\end{array}$ & $\begin{array}{c}-0.133 \\
(0.179)\end{array}$ \\
\hline HHIncome & $\begin{array}{c}-0.009 \\
(0.007)\end{array}$ & $\begin{array}{l}-0.011^{* *} \\
(0.011)\end{array}$ & $\begin{array}{l}-0.021^{* *} \\
(0.009)\end{array}$ & $\begin{array}{l}-0.095^{* * *} \\
(0.020)\end{array}$ & $\begin{array}{c}-0.004 \\
(0.017)\end{array}$ & $\begin{array}{l}-0.194^{* * *} \\
(0.039)\end{array}$ \\
\hline HHAge & $\begin{array}{c}-0.002 \\
(0.002)\end{array}$ & $\begin{array}{c}-0.001 \\
(0.004)\end{array}$ & $\begin{array}{l}-0.006^{*} \\
(0.003)\end{array}$ & $\begin{array}{l}-0.035^{* * *} \\
(0.006)\end{array}$ & $\begin{array}{l}-0.048^{* * *} \\
(0.006)\end{array}$ & $\begin{array}{l}-0.056^{* * *} \\
(0.013)\end{array}$ \\
\hline Intercept & $\begin{array}{l}-2.650^{* * *} \\
(0.213)\end{array}$ & $\begin{array}{l}-3.611^{\text {*** }} \\
(0.332)\end{array}$ & $\begin{array}{l}-1.928^{* * *} \\
(0.267)\end{array}$ & $\begin{array}{l}29.781^{* * *} \\
(0.563)\end{array}$ & $\begin{array}{l}28.999^{* * *} \\
(0.502)\end{array}$ & $\begin{array}{l}31.095^{* * *} \\
(1.119) \\
\end{array}$ \\
\hline FruitVegShare Marginal Effect ${ }^{\mathrm{a}}$ & -0.090 & -0.029 & -0.120 & & & \\
\hline$\varepsilon$ FruitVegShare $^{\mathrm{b}}$ & & & & -1.397 & -2.184 & 1.177 \\
\hline Adj. $R^{2}$ & 0.024 & 0.023 & 0.018 & 0.050 & 0.061 & 0.024 \\
\hline $\mathrm{N}$ & 18,562 & 13,809 & 15,824 & 18,355 & 13,647 & 15,578 \\
\hline
\end{tabular}

Robust standard errors in parentheses.

*** Denotes that the coefficient estimate is significant at the 0.01 level. **: At the 0.05 level. *: At the 0.10 level.

${ }^{a}$ Marginal effects are calculated based on the estimated coefficient on FruitVegShare for the logit regressions.

${ }^{\mathrm{b}}$ Elasticities are calculated at the sample mean values for all variables. Given our regression specification, this corresponds to $\hat{\beta}_{\text {FruitVegShare }}\left(\frac{\overline{\text { FruitVegShare }}}{\overline{\text { AdultBMI}}}\right)$, for the AdultBMI coefficient.

${ }^{c}$ The AdultBMI is the average BMI among the household heads, as calculated using their reported height and weight. For the male and female estimations, this usually corresponds to the BMI of a single adult. However, some households feature two (or more) household heads of the same gender, and in this case AdultBMI is also an average. 
increase in FruitVegShare is associated with a decrease in BMI of nearly five units, which translates into approximately a 5 percent decrease based on the elasticity. However, the coefficient on BMI for female household head is insignificant. Across other covariates, no systematic patterns emerge between the genders, although in some cases estimated coefficients differ significantly in magnitude.

We also estimate equations (3) and (4) using the full MedProfiler dataset, with both year effects and household fixed effects. This enables us to use a considerably larger sample size and examine how the key variables influence the health outcomes of the same households over time, as we are no longer restricted to using ailment data from 2012 alone. Therefore, when using the 2010-2012 ailment scores, we estimate equations (3) and (4) with the fixed effects Panel approach to control for the un-observables such as household genetics and the overall demand for health. To eliminate the incidental parameter problem in the fixed effects logit model specified in equation (3), we used the conditional maximum likelihood estimation method suggested in Cameron and Trivedi (2005). Our dasataset is strongly balanced, as we include only those households that participated consistently from 20102012. In addition, we detected no autocorrelations with the errors. ${ }^{10}$ Table 3 reports the results with fixed effects.

The fixed effect findings lend robustness to our logistic and OLS results and reinforce our key estimated relationships. Specifically, we find that increased fruit and vegetable expenditure shares are associated with statistically significant reductions in both Obesity and AdultBMI, for the full samples. The same association is also found in female head Obesity and male head BMI. The FruitVegShare coefficients indicate larger impacts for women than the entire sample with respect to obesity status, which may help inform the optimal implementation strategies for educational or promotional efforts aimed at improving fruit and vegetable intake. In contrast with the results of (2), the impact of FruitVegShare on BMI for female household head is found to be negative and significant.

Furthermore, consistent with the logistic and OLS results, the ExerciseScore coefficients show negative and significant impact on both Obesity and AdultBMI in the fixed effects results. Interestingly, HHAge is positively associated with our measures of body weight. Thus, aging can result in higher incidence of obesity and increased average BMI among Americans.

The gender-specific results call for a closer examination, ideally using data with more diverse demographics. We consistently estimate negative and significant impacts for the overall samples, for both Obesity and AdultBMI. When estimating equations (1) and (2), we find no significant impact of fruit and vegetable expenditures on obesity for men or for average BMI for

\footnotetext{
10 We conducted the Wooldridge test for autocorrelation. The resulting F value is 0.039 , with a p-value of 0.84 . Therefore, the null hypothesis of no serial correlation could not be rejected.
} 


\begin{tabular}{|c|c|c|c|c|c|c|}
\hline & \multicolumn{3}{|c|}{ Obesity } & \multicolumn{3}{|c|}{ AdultBMI } \\
\hline & \multicolumn{3}{|c|}{ Estimation Technique: Logit } & \multicolumn{3}{|c|}{ Estimation Technique: OLS } \\
\hline & Entire Sample & $\operatorname{Men}^{c}$ & Women & Entire Sample & $\operatorname{Men}^{\mathrm{d}}$ & Women \\
\hline FruitVegShare & $\begin{array}{l}-1.527^{* *} \\
(0.647)\end{array}$ & $\begin{array}{c}-0.037 \\
(0.985)\end{array}$ & $\begin{array}{c}-0.803 \\
(0.762)\end{array}$ & $\begin{array}{c}-1.441^{*} \\
(0.811)\end{array}$ & $\begin{array}{l}-1.679^{* *} \\
(0.757)\end{array}$ & $\begin{array}{l}-3.955^{* *} \\
(1.818)\end{array}$ \\
\hline ExerciseScore & $\begin{array}{l}-0.107^{* *} \\
(0.038)\end{array}$ & $\begin{array}{c}-0.101^{*} \\
(0.058)\end{array}$ & $\begin{array}{c}-0.089^{* *} \\
(0.046)\end{array}$ & $\begin{array}{c}-0.215^{*} \\
(0.087)\end{array}$ & $\begin{array}{l}-0.091^{* *} \\
(0.045)\end{array}$ & $\begin{array}{l}-0.220^{* * *} \\
(0.195)\end{array}$ \\
\hline VitaminScore & $\begin{array}{c}-0.030 \\
(0.042)\end{array}$ & $\begin{array}{l}0.022 \\
(0.065)\end{array}$ & $\begin{array}{c}-0.015 \\
(0.051)\end{array}$ & $\begin{array}{l}0.025 \\
(0.091)\end{array}$ & $\begin{array}{l}0.009 \\
(0.048)\end{array}$ & $\begin{array}{l}0.069 \\
(0.206)\end{array}$ \\
\hline Omega3Score & $\begin{array}{l}0.016 \\
(0.040)\end{array}$ & $\begin{array}{l}0.076 \\
(0.058)\end{array}$ & $\begin{array}{c}-0.066 \\
(0.047)\end{array}$ & $\begin{array}{c}-0.105 \\
(0.084)\end{array}$ & $\begin{array}{c}-0.047 \\
(0.044)\end{array}$ & $\begin{array}{c}-0.080 \\
(0.188)\end{array}$ \\
\hline HHAge & $\begin{array}{l}-0.071^{* * *} \\
(0.007)\end{array}$ & $\begin{array}{l}-0.071^{* * *} \\
(0.011)\end{array}$ & $\begin{array}{l}-0.091^{* * *} \\
(0.009)\end{array}$ & $\begin{array}{c}0.084^{* * *} \\
(0.016)\end{array}$ & $\begin{array}{c}-0.011 \\
(0.008)\end{array}$ & $\begin{array}{l}0.007 \\
(0.038)\end{array}$ \\
\hline Intercept & & & & $\begin{array}{l}23.643^{* * *} \\
(0.761)\end{array}$ & $\begin{array}{l}29.617^{* * *} \\
(0.475)\end{array}$ & $\begin{array}{l}28.197^{* * *} \\
(1.806)\end{array}$ \\
\hline FruitVegShare Marginal Effect ${ }^{a}$ & -0.028 & -0.001 & -0.004 & & & \\
\hline$\varepsilon$ FruitVegShare $^{\mathrm{b}}$ & & & & -0.699 & -0.777 & -1.849 \\
\hline Overall $\mathrm{R}^{2}$ & & & & 0.001 & 0.018 & 0.009 \\
\hline Number of HHs/year & 13,998 & 6,510 & 9,933 & 9,792 & 8,467 & 8,067 \\
\hline
\end{tabular}

Robust standard errors in parentheses.

*** Denotes that the coefficient estimate is significant at the 0.01 level. **: At the 0.05 level. *: At the 0.10 level.

${ }^{a}$ Marginal effects are calculated based on the estimated coefficient on FruitVegShare for the logit regressions.

b Elasticities are calculated at the sample mean values for all variables. Given our regression specification, this corresponds to $\hat{\beta}_{\text {FruitvegShare }}\left(\frac{\overline{F r u i t V e g S h a r e}}{\overline{\text { AdultBMI }}}\right)$, for the AdultBMI coefficient.

${ }^{c}$ The AdultBMI is the average BMI among the household heads, as calculated using their reported height and weight. For the male and female estimations, this usually corresponds to the BMI of a single adult. However, some households feature two (or more) household heads of the same gender, and in this case AdultBMI is also an average.

${ }^{\mathrm{d}}$ In the fixed effects logit model, neither the intercept term nor the pseudo- $\mathrm{R}^{2}$ are estimated or calculated. 
women. When estimating equations (3) and (4), with household fixed effects, neither of the gender-based estimations yield significant associations with FruitVegShare. The lack of significant findings for male head Obesity and female head BMI may be due to the fact that the MedProfiler data are selfreported. There may be important systematic differences between men and women with respect to reporting weight or obesity status, and this possibility warrants investigation to inform future research. Epidemiological research on the mechanisms affecting body weight and how these differ by gender, as well as other interdisciplinary approaches, may help inform these results.

Our results indicate that, when controlling for lifestyle choices, and a host of demographic factors, there is a strong association between fruit and vegetable expenditures and obesity incidence or BMI. Therefore, policy and educational efforts aimed toward increasing fruit and vegetable purchases at the retail level, particularly in supermarkets, may be worth the cost of implementation, owing to the expected decrease in health care expenditures over the coming years. Additional research may help demonstrate whether such expenditures at the national level are justified, given that we find a robust and significant impact on average adult BMI. However, efforts may also be targeted to areas of above-average obesity levels, given that we find the discrete classification of obesity is more sensitive to changes in fruit and vegetable purchases than is BMI. Richards and Hamilton (2012) argue that obesity policy would be best aimed at informing consumers about the long-term implications of their behavior, based on people's effective discount rate in making decisions. Our research provides a unique contribution by quantifying the impacts of multiple years of household food purchase behavior on adult obesity outcomes and BMI.

\section{Conclusions and Future Work}

We use a rich and granular dataset on household food expenditures, paired with self-reported medical outcome data. The results indicate a robust, negative, and significant relationship between the share of total food expenditures on fruits and vegetables and the incidence of obesity as well as average adult BMI. We measure fruit and vegetable expenses as shares of total recorded food expenditures. We find that increasing household fruit and vegetable expenditure shares by one percentage point decreases the long run, multiyear incidence of adult obesity by approximately 9 percent and average adult BMI by 1.4 percent. These estimates are robust to specification choice.

We argue that the relatively poor average U.S. dietary quality motivates additional policy and educational efforts aimed toward increasing fruit and vegetable purchases among U.S. households. Marginal changes and improvements to fruit and vegetable purchasing behavior can be executed directly at the retail level too. Estimating the potential impacts of increased fruit and vegetable expenditures on health care costs or on the incidence of morbidity in the United States is beyond the scope of this study. However, 
such work is strongly motivated in future research as a means to estimate the expected returns from government or industry efforts to increase fruit and vegetable purchases.

Our research is not without limitations. Chief among them is the limited demographic variation in the IRI Panel, which is weighted toward older higher-income, well-educated, and white families. Given this restriction, we only have a limited capacity to observe food choices and health outcomes among low-income households and those eligible for food assistance programs. We are also, as noted, unable to observe food choices and expenditures outside the home, which have the potential to impact diet quality and health. Because we use point-of-sale data, we measure fruit and vegetable expenditures, not consumption. Therefore, we are unable to control for waste or food preparation methods, both of which may affect the amount of fruit and vegetable actually being consumed following the observed purchases. Lastly, we recognize there is a degree of inconsistency with respect to statistical significance of the gender-based results. Given our current resources, we are unable to provide a specific reason for that. An interdisciplinary research to study these gender effects in more detail might be helpful to inform the results.

Our analysis could be extended in a variety of ways. It would be useful to understand how increased expenditures on other food and beverage categories influence body weight. Certain food categories such as fruit juices or red meats have health implications that have yet to be resolved by the nutrition or epidemiological literature. Our dataset allows for investigations in these questions that extend beyond dietary recall data. Another potential application of this research is to examine if the impacts of fruit and vegetable purchases on body weight are equal, regardless of point of purchase. For example, it has been suggested in consumer surveys that fruit and vegetable quality is inferior in supercenters relative to supermarkets. If this were to be the case, we would expect smaller impacts of fruit and vegetable purchases on health, among supercenter shoppers.

\section{References}

Adelaja, A.O., R.M. Nayga, and T.C. Lauderbach. 1997. "Income and Racial Differentials in Selected Nutrient Intakes." American Journal of Agricultural Economics 79: 1452-1460.

Ahima, R.S., and M.A. Lazar. 2013. "The Health Risk of Obesity-Better Metrics Imperative." Science 341: 856-858.

Avenell, A., J.I. Broom, T.J. Brown, A. Poobalan, L.S. Aucott, S.C. Stearns, W.C. Smith, et al. 2004. "Systematic Review of the Long-term Effects and Economic Consequences of Treatments for Obesity and Implications for Health Improvement." Health Technology Assessment 8: 1-182.

Blaylock, J., D. Smallwood, K. Kassel, J. Variyam, and L. Aldrich. 1999. “Economics, Food Choices, and Nutrition." Food Policy 24: 269-286.

Bodnar, L.M., and A.M. Siega-Riz. 2002. "A Diet Quality Index for Pregnancy Detects Variation in Diet and Differences by Socio-demographic Factors." Public Health Nutrition 5: 801-809. 
Bustillos, B., J.R. Sharkey, J. Anding, and A. McIntosh. 2008. "Availability of More Healthful Food Alternatives in Traditional, Convenience, and Nontraditional Types of Food Stores in Two Rural Texas Counties." Journal of the American Dietetic Association 109: 883-889.

Cameron, A.C., and P.K. Trivedi. 2005. Microeconometrics: Methods and Applications. New York: Cambridge University Press.

Capacci, S., and M. Mazzocchi. 2011. "Five-a-day, A Price to Pay: An Evaluation of the UK Program Impact Accounting for Market Forces.” Journal of Health Economics 30(1): 87-98.

Cassady, D., K.M. Jetter, and J. Culp. 2007. "Is Price a Barrier to Eating More Fruits and Vegetables for Low-income Families?" Journal of the American Dietetic Association 107: 1909-1915.

Carlson, A., M. Lino, and T. Fungwe. 2007. "The Low-cost, Moderate-cost, and Liberal Food Plans." (CNPP-20). U.S. Department of Agriculture, Center for Nutrition Policy and Promotion.

Centers for Disease Control and Prevention (CDC). 2011. Most Americans with High Blood Pressure and High Cholesterol at Unnecessary Risk for Heart Attack and Stroke. Vital Signs February 1, 2011. Available at http://www.cdc.gov/media/releases/2011/ p0201_vitalsigns.html (accessed March 15, 2019)

- 2014. National Diabetes Statistics Report 2014. Available at http://www.cdc.gov/ mmwr/preview/mmwrhtml/mm6135a3.htm

— 2017. Adult Obesity Prevalence Maps. Available at https://www.cdc.gov/obesity/data/ prevalence-maps.html (accessed March 15, 2019)

Center for Nutrition Policy and Promotion (CNPP). 2010. Dietary Guidelines for Americans 2010. Available at: http://www.cnpp.usda.gov/sites/default/files/dietary_guidelines_ for_americans/PolicyDoc.pdf (accessed March 15, 2019)

- 2013. Diet Quality of Americans in 2001-02 and 2007-08 as Measured by the Healthy Eating Index-2010. Nutrition Insight 51. Available at: http://www.cnpp.usda.gov/sites/ default/files/nutrition_insights_uploads/Insight51.pdf (accessed March 15, 2019)

Chen, D., E.C. Jaenicke, and R.J. Volpe. 2016. "Food Environments and Obesity: Household Diet Expenditure versus Food Deserts." American Journal of Public Health 106(5): 881-888.

Coleman-Jensen, A., C. Gregory, and A. Singh. 2014. "Household Food Security in the United States in 2013.” USDA-ERS Economic Research Report 2014 (173).

Dong, D., and B.H. Lin. 2009. "Fruit and Vegetable Consumption by Low-Income Americans." USDA Economic Research Service (USDA-ERS), Economic Research Report No. 70.

Finkelstein, E., J.G. Trogdon, J.W. Cohen, and W. Dietz. 2009. "Annual Medical Spending Attributable to Obesity: Payer and Service-specific Estimates." Health Affairs 28: w822-w831.

Flegal, K.M., M.D. Carroll, B.K. Kit, and C.L. Ogden. 2012. "Prevalence of Obesity and Trends in the Distribution of Body Mass Index among U.S. Adults, 1999-2010." Journal of the American Medical Association 307: 491-497.

_. 2016. "Trends in Obesity among Adults in the United States, 2005-2014." Journal of the American Medical Association 315: 2284-2291.

Gao, Z., X. Yu, and J.Y. Lee. 2013. "Consumer Demand for Diet Quality: Evidence from the Healthy Eating Index." Australian Journal of Agricultural and Resource Economics 57: 301-319.

Howard, B.V., L. Van Horn, J. Hsia, J.E. Manson, M.L. Stefanick, S. Wassertheil-Smoller, L.H. Kuller, et al. 2006. "Low-Fat Dietary Pattern and Risk of Cardiovascular Disease: the Women's Health Initiative Randomized Controlled Dietary Modification Trial." JAMA 295(6): 655-666.

Huang, T.T.K., K.J. Harris, R.E. Lee, N. Nazir, W. Born, and H. Kaur. 2003. "Assessing Overweight, Obesity, Diet, and Physical Activity in College Students." Journal of American College Health 52: 83-86. 
Kaiser, K.A., A.W. Brown, M.M. Bohan Brown, J.M. Shikany, R.D. Mattes, and D.B. Allison. 2014. "Increased Fruit and Vegetable Intake has no Discernible Effect on Weight Loss: A Systematic Review and Meta-Analysis." The American Journal of Clinical Nutrition 100: 567-576.

Kimmons, J., C. Gillespie, J. Seymour, M. Serdula, and H.M. Blanck. 2009. "Fruit and Vegetable Intake among Adolescents and Adults in the United States: Percentage Meeting Individualized Recommendations." The Medscape Journal of Medicine 11: 26.

Krebs-Smith, S. M., D.A. Cook, A.F. Subar, L. Cleveland, J. Friday, and L.L. Kahle. 1996. "Fruit and Vegetable Intakes of Children and Adolescents in the United States." Archives of Pediatrics and Adolescent Medicine 150: 81-86.

Leibtag, E., and A. Kumcu. 2011. "The WIC Fruit and Vegetable Cash Voucher: Does Regional Price Variation Affect Buying Power?" USDA Economic Research Service Economic Information Bulletin No. 75.

Leung, C.W., E.L. Ding, P.J. Catalano, E. Villamor, E.B. Rimm, and W.C. Willett. 2012. "Dietary Intake and Dietary Quality of Low-Income Adults in the Supplemental Nutrition Assistance Program." The American Journal of Clinical Nutrition 96(5): 977-988.

Mancino, L., and C. Newman. 2007. "Who Has Time to Cook? How Family Resources Influence Food Preparation." USDA Economic Research Service Economic Research Report No. 40.

Mandal, B., and L.M. Powell. 2014. "Child Care Choices, Food Intake, and Children's Obesity Status in the United States." Economics \& Human Biology 14: 50-61.

Morgan, K.J. 1986. "Socioeconomic Factors Affecting Dietary Status: An Appraisal." American Journal of Agricultural Economics 68: 1240-1246.

Mozaffarian, D., T. Hao, E.B. Rimm, W.C. Willett, and F.B. Hu. 2011. "Changes in Diet and Lifestyle and Long-term Weight Gain in Women and Men." New England Journal of Medicine 364(25): 2392-2404.

Nordmann, A.J., A. Nordmann, M. Briel, U. Keller, W.S. Yancy, B.J. Brehm, and H.C. Bucher. 2006. "Effects of Low-Carbohydrate vs Low-Fat Diets on Weight Loss and Cardiovascular Risk Factors: a Meta-Analysis of Randomized Controlled Trials." Archives of Internal Medicine 166(3): 285-293.

Ogden, C.L., M.D. Carroll, B.K. Kit, and K.M. Flegal. 2015. "Prevalence of Childhood and Adult Obesity in the United States, 2011-2012." Journal of the American Medical Association 311: 806-814.

Okrent, A.M., and J.P. MacEwan. 2014. "The Effects of Prices, Advertising, Expenditures, and Demographics on Demand for Nonalcoholic Beverages." Agricultural and Resource Economics Review 43(1): 31-52.

Oyebode, O., V. Gordon-Dseagu, A. Walker, and J.S. Mindell. 2014. "Fruit and Vegetable Consumption and All-cause, Cancer and CVD Mortality: Analysis of Health Survey for England Data." Journal of Epidemiology and Community Health 68: 856-862.

Powell, L.M. 2009. "Fast Food Costs and Adolescent Body Mass Index: Evidence from Panel Data." Journal of Health Economics 28(5): 963-970.

Richards, T.J., and P.M. Patterson. 2005. "A Bilateral Comparison of Fruit and Vegetable Consumption: United States and Canada." Journal of Agricultural and Resource Economics 30: 333-349.

Richards, T.J., and S.F. Hamilton. 2012. “Obesity and Hyperbolic Discounting: an Experimental Analysis." Journal of Agricultural and Resource Economics 37: 181-198.

Rose, D., and R. Richards. 2004. "Food Store Access and Household Fruit and Vegetable Use among Participants in the U.S. Food Stamp Program." Public Health Nutrition 7: 1081-1088.

Rowland, M.L. 1990. "Self-Reported Height and Weight." American Journal of Clinical Nutrition 52: 1125-1133.

Schroeter, C., S. Anders, and A.C. Carlson. 2013. "The Economics of Health Behavior and Vitamin Consumption." Applied Economic Perspectives \& Policy. Special issue on "The Economics of Lifestyles, Obesity, and Nutrition." 35(1): 125-150. 
Sarma, S., G.S. Zaric, M.K. Campbell, and J. Gilliland. 2014. “The Effect of Physical Activity on Adult Obesity: Evidence from the Canadian NPHS Panel." Economics \& Human Biology 14:1-21.

Stewart, H., N. Blisard, and D. Joliffe. 2003. “Do Income Constraints Inhibit Spending on Fruits and Vegetables among Low-Income Households?" Journal of Agricultural and Resource Economics 28: 465-480.

Te Morenga, L., S. Mallard, and J. Mann. 2013. “Dietary Sugars and Body Weight: Systematic Review and Meta-analyses of Randomized Controlled Trials and Cohort Studies." BMJ 346: e7492.

U.S. Department of Agriculture and U.S. Department of Health and Human Services. 2015. Current Eating Patterns in the United States. Available at: https://health.gov/ dietaryguidelines/2015/guidelines/chapter-2/current-eating-patterns-in-the-unitedstates/ (accessed March 2019)

Van Duyn, M.A.S., and E. Pivonka. 2000. "Overview of the Health Benefits of Fruit and Vegetable Consumption for the Dietetics Professional: Selected Literature." Journal of the American Dietetic Association 100(2000): 1511-1521.

Vartanian, L.R., M.B. Schwartz, and K.D. Brownell. 2007. "Effects of Soft Drink Consumption on Nutrition and Health: A Systematic Review and Meta-Analysis." American Journal of Public Health 97(4): 667-675.

Volpe, R., and A. Okrent. 2012. "Assessing the Healthfulness of Consumers' Grocery Purchases." USDA Economic Research Service Economic Information Bulletin 102.

Volpe, R., A. Okrent, and E. Leibtag. 2013. "The Effect of Supercenter-Format Stores on the Healthfulness of Consumers' Grocery Purchases." American Journal of Agricultural Economics 95(3): 568-589.

Volpe, R., E.C. Jaenicke, and L. Chenarides. 2018. "Store Formats, Market Structure, and Consumers' Food Shopping Decisions." Applied Economic Perspectives and Policy 40(4): 672-694.

Wang, Y., and M.A. Beydoun. 2007. "The Obesity Epidemic in the United States-Gender, Age, Socioeconomic, Racial/Ethnic, and Geographic Characteristics: A Systematic Review and Meta-Regression Analysis." Epidemiologic Reviews 29(1): 6-28.

Wang, D.D., C.W. Leung, Y. Li, E.L. Ding, S.E. Chiuve, F.B. Hu, \& W.C. Willett. 2014. "Trends in Dietary Quality among Adults in the United States, 1999 through 2010." JAMA Internal Medicine 174(10): 1587-1595.

Wang, M., Y. Yi, B. Roebothan, J. Colbourne, V. Maddalena, P.P. Wang, and G. Sun. 2016. "Body Mass Index Trajectories among Middle-Aged and Elderly Canadians and Associated Health Outcomes." Journal of Environmental and Public Health 2016: 7014857.

Wilde, P.E., P.E. McNamara, and C.K. Ranney. 1999. "The Effect of Income and Food Programs on Dietary Quality: A Seemingly Unrelated Regression Analysis with Error Components." American Journal of Agricultural Economics 81: 959-971. 